\title{
CUERPOS PARA EXPERIMENTAR. OBJETIVACIÓN MÉDICA, POSITIVISMO Y ELIMINACIÓN ÉTNICA EN ARGENTINA (1860-1890)*
}

\author{
María Silvia Di Liscia \\ Depto. de Historia, FCH/UNLPam \\ Santa Rosa, Argentina
}

\section{RESUMEN}

Este trabajo analiza los mecanismos utilizados por determinados especialistas en medicina para determinar científicamente la inferioridad de las etnias nativas, especialmente las de la Pampa y Patagonia. Se trata de un fenómeno común al pensamiento posivista argentino de la segunda mitad del siglo XIX que se refleja fundamentalmente en los trabajos de varios médicos, como Paolo Mantegazza, Benjamín Dupont, José Franceschi y Lucio Meléndez, cuyo discurso ejemplifica el etnocentrismo y la aplicación de teorías biologicistas en el ámbito nacional, consecuentes con el exterminio paralelo de los indígenas.

PALABRAS CLAVE: Argentina, siglo XIX, antropología.

\section{SUMMARY}

This paper analises the ways used by the physicians to support scientifically the inferior condition of the native people of the Pampa and Patagonia. Several physicians, like Paolo Mantegazza, Benjamin Dupont, José Franceschi and Lucio Meléndez, had a typical positivist ideology about the middle of the XIX ${ }^{\text {a }}$ Century in Argentina, conected with the aplication of the biological theory for the elimination of native people.

KEY WORDS: Argentina, $19^{\text {th }}$ century, anthropology.

\section{POSITIVISMO, INDÍGENAS Y NACIÓN ARGENTINA}

«El salvaje del Chaco, apoyado en el arco de su flecha, contemplará con tristeza el curso de la formidable máquina que le intima el abandono de aquellas márgenes.

\footnotetext{
* Este artículo es parte de la Tesis de Doctorado Itinerarios curativos. Saberes, prácticas y terapias médicas indígenas, populares y científicas (Región Pampeana, 1750-1910), presentada en el Instituto U. Ortega y Gasset (U. Complutense). Agradezco los comentarios realizados por Manuel Gutiérrez Estévez a una versión anterior.
} 
Resto infeliz de la criatura primitiva: decid adiós al dominio de vuestros pasados. La razón despliega hoy sus banderas sagradas en el país que no protegerá ya con asilo inmerecido la bestialidad de las razas» ${ }^{1}$. Las resonantes frases de Alberdi escritas en los años ' 50 se arraigaron firmemente en el escenario político argentino de treinta años después. Ante la imagen didáctica de un indígena que observa pasar un ferrocarril, Alberdi extendía magistralmente toda la teoría cientificista desarrollada en 1880, cuyos máximos exponentes fueron los intelectuales positivistas José M. Ramos Mexía, Carlos O. Bunge, Estanislado Zeballos, Francisco P. Moreno y que se observa también en el quehacer concreto de médicos como Paolo Mantegazza, José Franceschi, Benjamín Dupont y Lucio Meléndez, entre otros.

La necesidad de conquistar el territorio para la ciencia y la técnica decimonónica implicó un proceso simultáneo de eliminación étnica, donde las sociedades indígenas autónomas debían ser controladas definitivamente por el Estado nacional ${ }^{2}$. Si bien existieron proyectos similares durante toda la historia compartida de blancos e indios en la llanura pampeana, no tuvieron prioridad hasta la llegada a la presidencia de la nación de Julio A. Roca, quien a partir de la Campaña al Desierto desalojó a los indígenas de sus asentamientos en la Pampa, Buenos Aires y Córdoba, tomando prisioneros a una gran mayoría y concentrando a los restantes en la Patagonia para finalmente vencerlos en los años subsiguientes ${ }^{3}$.

La ciencia occidental otorgó la ideología necesaria para legitimar el dominio de los blancos, enraizado en profundas convicciones raciales. La población nativa, imaginariamente situada «aparte» y separada de la europea ${ }^{4}$, se presupuso incapaz de

1 AlBERDI, J. B. (1856), «Bases y puntos de partida para la organización política de la República Argentina», en: AlBerdI, J. B., Organización política y económica de la Confederación Argentina, Bezanzon, 1856, p. 54.

2 Los españoles no lograron establecerse en el sur de Chile, denominado Araucanía, ni en los enormes territorios desde Neuquén a Buenos Aires y desde Córdoba y Santa Fé hasta el extremo sur del continente, que quedaron bajo el control de diferentes parcialidades indígenas. El uso del caballo como medio de transporte supuso un aumento de la peligrosidad indígena en los poblados blancos fronterizos, ya que los malones, ataques violentos en busca de ganado y de cautivos, fueron la expresión más notable de la presión indígena sobre las fronteras, lo cual generó y fortaleció a lo largo del tiempo el imaginario blanco del indígena como ladrón, salvaje y belicoso, impregnando significativamente la mayoría de los relatos e informes sobre indios. Sobre caracterizaciones generales de las poblaciones indígenas, ver MANDRINI, R. (1991), «La sociedad indígena de las Pampas del siglo XIX», M. Lischetti, ed., Antropología, Buenos Aires, pp. 309-336. Respecto a la pertenencia étnica, ver PALERMO, M. A. (1994), «El revés de la trama. Apuntes sobre el papel de la mujer en las sociedades indígenas tradicionales», Memoria Americana, Cuadernos de Etnohistoria, 3, pp. 67-68. Cuando no es posible acercar una conceptualización de las parcialidades étnicas, se considera en este artículo a los miembros de las sociedades indígenas bajo distintas denominaciones generales, aludiéndose así a araucanos, mapuches o pampas.

3 Sobre la organización de la Campaña al Desierto, ver OlASCOAGA, M. (1881), La conquête de la Pampa. Recueil de documents relatifs a la campagne du Rio Negro, Buenos Aires, p. XX.

4 En la actualidad, diversos estudios enfatizan una historia conjunta de blancos e indios, con permanentes contactos comerciales y políticos, donde los indios integraron los ejércitos provinciales o 
llevar a feliz término los desafíos económicos y sociales de finales del XIX y ese parecer se justificó a partir de un análisis científico. Los indígenas se transformaron en objetos y en muchos casos, dada su desaparición como fuerza demográfica, en «objetos de museo». La medicina académica, así como otras ramas derivadas del estudio médico - la antropología médica y la psiquiatría—, completaron la despersonalización de los indios a partir de su cosificación científica. Los «cuerpos» indígenas se convirtieron en pruebas de teorías médicas, donde era posible experimentar remedios y prácticas susceptibles de ser usadas después en otros pacientes. Este artículo analiza específicamente la conformación de un discurso médico inferiorizante de los indígenas de la Pampa y Patagonia argentinas a nivel biológico y, consecuentemente, a nivel cultural y social. Se utilizan como fuentes la obra de diversos médicos que tuvieron contacto directo con indígenas, aparecida en textos y revistas científicas argentinas entre 1870-1890.

A mediados del siglo XIX, el auge positivista tuvo como consecuencia la generación de un discurso de reestructuración del mundo por el cual se intentó justificar biológicamente la supuesta inferioridad de ciertos seres humanos. El enorme peso de las teorías científicas marginadoras puede atestiguarse en estudios sobre criminales, enfermos mentales y razas «degeneradas», que tuvieron un impacto directo en la elaboración posterior de políticas sociales ${ }^{5}$.

Su aplicación concreta en el ámbito pampeano planteó sin demasiadas contradicciones la necesidad de eliminar a los «bárbaros» y «salvajes», según la escala evolutiva del pensamiento positivo. Así se sucedieron las opiniones de diferentes escritores, militares, políticos y también viajeros extranjeros sobre la necesidad de «blanquear» la población nacional, eliminando la población nativa y evitando en determinadas ocasiones el mestizaje o haciéndolo selectivamente. Según Biagini, los positivistas argentinos estuvieron lejos de concordar absolutamente en todos los puntos pero compartieron en general el reduccionismo fisiologista, mecanicista o cientificista, con inclinaciones elitistas, europeístas y racistas ${ }^{6}$.

A partir de 1870, los «biologistas sociales» expresaron enfáticamente su espíritu positivo al avalar la ideología del progreso, articulándola casi como una religión

nacional y participaron políticamente apoyando a determinados sectores y partidos. Ver al respecto RATTO, S. (1994), «El negocio pacífico de indios. La frontera bonaerense durante el gobierno de Rosas», Siglo XIX, Revista de Historia, México, 15, pp. 25-47 y BECHIS, M. (1998), «Fuerzas indígenas en la política criolla del siglo XIX», GOLDMAN, N.y SALVATORE, R. Caudillismos rioplatenses. Nuevas miradas a un viejo problema, Buenos Aires, pp. 293-317.

5 PESET, J. L. (1986), Ciencia y marginación. Sobre negros, locos y criminales, Barcelona.

6 El positivismo realizó también aportes singulares en aspectos muy diversos, como un análisis más profundo de la realidad con vistas a formular la identidad argentina, una estimación de la ciencia en sí misma y de sus aplicaciones concretas para mejorar el nivel de vida, marchando a la vanguardia científica del momento. En BiAgini, H. (1985), comp. El movimiento positivista argentino, Buenos Aires, Presentación, pp. 16-18. 
secular. Su fervor puede ejemplificarse en una frase de Eduardo Holmberg, demostrando la justicia de la guerra contra los indígenas: «Acabamos con los indios porque la Ley de Malthus está arriba de las opiniones individuales» ${ }^{7}$, en Hermann Burmeisteir, que colocaba a los indios en la «escala más baja de la sociedad humana» de la cual «...nunca ascenderán a otra superior porque no comprenden el valor de la cultura $\rangle^{8}$ o bien en José M. Ramos Mexía, quien explicaba su desaparición como parte de un proceso natural y biológico, donde los más fuertes sobreviven a los más débiles9.

Otros, como Carlos O. Bunge, justificaron a principios del XX la eliminación étnica producida años antes al otorgar a los indios caracteres negativos, como la venganza, la indolencia y la rapacidad. La prueba de estos calificativos estaba en la realidad: «Lo que es es, con o sin prejuicios». En la época de los caudillos se había producido «naturalmente» una purificación racial: «...el alcoholismo, la viruela, y la tuberculosis — ¡benditos sean! — habían diezmado a la población indígena y africana de la provincia capital, depurando sus elementos étnicos, europeizándolos» ${ }^{10}$.

Sarmiento, en su obra póstuma Conflictos y armonías, planteaba asimismo que los indígenas americanos debían ser respetados como fósiles vivientes y a la vez aseguraba que distintos estudios científicos establecían al indio como apático, miedoso y abyecto, «...incapaz de concebir y raciocinar, es ignorante de sí mismo y de lo que sucede a su alrededor..». Por otra parte, su amor a los bosques y a la vida salvaje no significaba amor a la libertad sino que se relacionaba con la melancolía y superstición ${ }^{11}$. Sarmiento afirmaba el sensualismo de los pampas, su extrema dependencia del alcohol y la desidia de los varones, que dejaban a las mujeres todas las tareas productivas, estableciendo además que los indios de la Pampa carecían de organización política, de moral, higiene y autoridad, salvo para robar y hacer la guerra ${ }^{12}$. Ante el contacto con la civilización, los indios decaen, no sólo porque se abaten sus bosques y cambia la contextura del aire por falta de emanaciones sino porque están

7 MonserRat, M. (1986), «La presencia evolucionista en el positivismo argentino», Quipu, 3, $\mathrm{n}^{\mathrm{o}} 1$, p. 97.

8 Burmeisteir, H. (1943), Viaje por los Estados del Plata, 1857-1860, Buenos Aires, T. II, p. 29. Burmeisteir fue un destacado naturalista prusiano, que realizó una expedición a mediados del XIX por las provincias argentinas. Fue también director del Museo de Buenos Aires.

9 Ramos MexíA, J. M. (1915), Las neurosis de los hombres célebres de la República Argentina, Buenos Aires. Fue escrito en 1878. Ramos Mexía, médico, fue una de las personalidades más importantes de la generación del ' 80 y uno de los ejemplos más claros del positivismo en Argentina.

10 Bunge, C. O. (1926), Nuestra América, Madrid, pp. 135, 160 y 172. El texto fue escrito en 1903. Bunge era abogado; tuvo destacada actuación como político, jurista y escritor a finales del siglo XIX.

11 SARmiento, D. F. (1915), Conflicto y armonías de las razas en América, Buenos Aires, p. 85. La obra fue escrita en 1882, seis años antes de su muerte. Aunque Sarmiento no puede considerarse positivista, ya que no responde en todo al ideario de Spencer, representa en ciertos conceptos el pensamiento científico de la segunda mitad del siglo XIX, sobre todo en su vertiente biologicista.

12 Ibidem, pp. 108-110. 
«...destinados por la Providencia a desaparecer de la lucha por la existencia, en presencia de las razas superiores» ${ }^{13}$.

\section{MEDIR Y CLASIFICAR}

La ciencia decimonómica, a través de una jerarquía racial que ponía en lo alto la civilización occidental, comenzó paulatinamente a considerar a los habitantes de otras partes del mundo que participaban de un diferente desarrollo tecnológico y social como «piezas de museo». Los nativos americanos entraban dentro de esta clasificación y no fueron percibidos como contemporáneos sino que se transformaron imaginariamente en la base de la civilización, que había permanecido sin cambios siglo tras siglo hasta llegar al presente.

Un ejemplo al respecto puede observarse en Francisco P. Moreno, quien en su viaje por la Patagonia realizó en varias oportunidades excavaciones arqueológicas en cementerios araucanos y tehuelches, recolectando huesos y cráneos ${ }^{14}$. Como director del Museo de Ciencias Naturales de La Plata, Moreno admitió en él no sólo el numeroso material palentológico y arqueológico recogido sino a los mismos indígenas. Los caciques Foyel, Sayhueque e Inacayal junto con sus familias fueron rescatados por el propio antropólogo de la isla Martín García, donde funcionó un penal para confinar los prisioneros luego de la Conquista al Desierto. Moreno los consideraba «...muestras vivientes de estadios culturales en vías de extinción»y, a su muerte, integraron en forma literal las piezas del Museo bonaerense. El esqueleto de Inacayal formó parte de la colección de hombres patagónicos como arquetipo racial ${ }^{15}$.

En el relato de la expedición española de Manuel Almagro y Francisco Paula Martínez en 1862 consta que Bartolomé Mitre, en ese momento presidente argentino, trajo ante los científicos a «...varios jóvenes indios de las tolderías de la Patagonia y del Gran Chaco» que él había hecho venir para educarlos y luego reenviarlos a sus comunidades ${ }^{16}$. Los españoles midieron a los indígenas y llevaron de vuelta a su patria, junto con las momias del Perú y Bolivia y los objetos de los sepulcros, gran

13 SARMIENTO (1915), p. 310.

14 Moreno, F. P. (1874), «Cementerios y paraderos prehistóricos en la Patagonia», Anales Científicos Argentinos, año 1, 1, pp. 2-16.

15 QuiJadA, M. (1998), «Ancestros, ciudadanos, piezas de museo. Francisco P. Moreno y la articulación del indígena en la construcción nacional argentina», Revista del EIAL, vol 9, 2, p. 35.

16 Almagro, M. (1984), La comisión científica del Pacífico. Viaje por Sudamérica y recorrido del Amazonas, 1862-1866, Barcelona, pp. 22-23. Quizás a estos mismos hijos de indígenas se refiera Zeballos al explicar la imposibilidad de educarlos de algún modo ya que ni bien vuelven a las tolderías, se comportan como un indígena más y olvidan toda la influencia civilizatoria. El autor alude específicamente al «hijo de Tripailev, educado en Buenos Aires por cuenta del estado» (Zeballos, E. (1881), Descripción amena de la República Argentina, Buenos Aires, p. 94). 
cantidad de cráneos de araucanos. Todas estas piezas llegaron presumiblemente a formar parte de los fondos de algunos museos del otro lado del Atlántico ${ }^{17}$.

También Estanislao Zeballos, quien recorrió pocos años después de la Conquista los territorios que habían pertenecido a los indígenas, aplicó a estos las teorías positivistas vigentes en la época. La testificación iconográfica y la medición corporal fue la metodología utilizada para hacer constar la «realidad», evitando en consecuencia un falseamiento de los datos. En la toldería del cacique mapuche Quiñelev, luego de medir la talla de los varones, se mofaba de su baja estatura y de su «facha de soberanos ${ }^{18}$. También expresaba con cierta liviandad ante un auditorio que en la época acordaría con el autor, la forma de engaño que utilizó en varias oportunidades para hacerse con «reliquias» indias al saquear los cementerios, llevando consigo cráneos - entre ellos, como un trofeo no exento de morboso interés, el del famoso cacique Calfucurá- $\mathrm{y}$ objetos de la codiciada platería ranquel ${ }^{19}$.

La antropometría se utilizó como base científica para apoyar criterios de discriminación dictados por el orden biológico. Paul Broca y Rudolf Virchow la emplearon para justificar la inferioridad femenina a partir de una capacidad craneal inferior o bien para establecer científicamente la base ideológica del positivismo, en el sentido de desarrollo lineal humano desde los primitivos a los civilizados. El estudio de los indígenas americanos, sobre todo los del Cono Sur, fue en cierta medida la apoyatura de las teorías antropológicas europeas.

Las mediciones de cráneos de indígenas le permitían a Carlos Marelli confirmar las teorías de Virchow. La baja capacidad craneana de pampas y araucanos daba indicios de la menor energía intelectual contenida en relación con las «razas superiores, término obligado de la comparación ${ }^{20}$. En un trabajo similar, Debenedetti asumía en los araucanos un predominio braquicéfalo, expresando que el ángulo facial era muy similar al del chimpancé ${ }^{1}$. En suma, el testimonio iconográfico así como las pruebas científicas objetivas, otorgadas por la antropometría, comprobaba las teorías positivistas. De igual manera sucedió con la investigación médica, según se analiza a continuación.

17 Sobre el viaje de M. Almagro y F. Paula Martínez, ver la completa obra de PUIG SAMPER, M. (1988), Crónica de una expedición romántica al Nuevo Mundo, Madrid. Según el autor, los materiales de la expedición fueron interpretados por otra generación de antropólogos hacia finales del siglo y quedaron recogidos en las colecciones del Museo Antropológico y del Museo Arqueológico de Madrid.

18 ZeBALlos (1881), pp. 71-73. Zeballos intervino directamente en la Campaña al Desierto como ingeniero y su interés era levantar una carta geográfica del territorio. Es fundador de la publicación de la Sociedad Científica, los Anales Cientificos Argentinos y escritor de numerosas obras sobre ranqueles y salineros.

19 Ibidem, p. 183.

20 MARELLI, C. (1915), «La capacidad del cráneo de los aborígenes en la Argentina», Boletín de la Sociedad Physis, Buenos Aires, 8, pp. 540-567.

21 DebenedetTi, E. (1909), «Anomalías y triángulo facial en cráneos de indios y otras razas existentes en el Museo de La Plata», La Semana Médica, XVI, V. 14, pp. 471-478. 


\section{LA «ESENCIA» INDÍGENA. INSENSIBILIDAD CORPORAL, INFERIORIDAD FÍSICA Y} MORAL

En obras y relatos de sus experiencias de campo, diversos especialistas que actuaron en el territorio argentino definían un «ser» indígena que condicionaba la mirada general sobre la ciencia propia y los conocimientos ajenos. Lo que los indios «son» es lo que son sus cuerpos, lo que sienten y como lo sienten, las enfermedades que pueden sufrir y los remedios a los que pueden acceder. Por ejemplo, Alfred Ebelot, ingeniero francés contratado por el gobierno bonaerense en la década del '70, expresaba que los pampas y ranqueles tienen un «vigor negativo»; son «duros pero no robustos»»; su sobriedad no es meritoria sino recurso de haraganes y no son capaces de realizar un trabajo regular. Ebelot agregaba en sus consideraciones esencialistas que los indios «...son sutiles y astutos como zorros, clarividentes como niños, pero como niños pervertidos» ${ }^{22}$.

Paolo Mantegazza, uno de los primeros estudiosos de la antropología médica en Italia, publicó entre 1858 y 1860 las Cartas médicas sobre la América meridional, fruto de recopilaciones durante su estadía entre los años 1854-1857 en el norte y este de Argentina, donde trabajó como médico ${ }^{23}$. Tanto en Entre Ríos como en Salta, Tucumán y en los numerosos viajes realizados a otras regiones de Argentina, Mantegazza explicaba que tuvo contacto directo con indígenas de diversas etnias. Su familiaridad con abipones, mocovíes, guaraníes, caniguas, pampas, araucanos, chiriguanos, matacos, calchaquíes, quichuas, aymará, tobas y guajajaras le permitía afirmar de manera contundente acerca de la naturaleza física y moral de los nativos. Explicaba que «...el indio de la América Meridional es un hombre de escasa sensibilidad, descontento de sí mismo; taciturno, silencioso, desconfiado, fríamente cruel; tierno a veces y activo, sobrio por necesidad o por inercia, así como en oportunidad voraz, pues que no aprende de la civilización más que los vicios, apasionado de los placeres y de la embriaguez. Supersticioso sin ser religioso, poco moral por su corta inteligencia; incapaz de alcanzar por sí mismo un alto grado de cultura y destinado a ser envuelto y a confundirse en el gran torrente de la civilización europea» ${ }^{24}$.

22 En EBelot, A. (1968), Relatos de frontera, Buenos Aires, pp. 30 y 173.

23 Mantegazza, P. (1949), Cartas médicas sobre la América Meridional, Buenos Aires, T. I y II. La obra fue editada originalmente en italiano y publicada periódicamente en la «Gazzetta Médica Lombarda» de Milán. Sobre la biografía del autor, ver Dalma, J. (1968), «Pablo Mantegazza en la medicina argentina», Primer Congreso de Historia de la Medicina Argentina, Buenos Aires, pp. 109-115. Un análisis de la obra de Mantegazza referida a medicina popular en COMELLES, J. (1997), «De las supersticiones a la medicina popular. La transición de un concepto religioso a un concepto médico», Medicina Popular e Antropoloxía da Saúde, Actas do Simposio Internacional en Homenaxe rendido a D. Antonio Fraguas, Santiago de Compostela, p. 247-280.

24 MANTEgAZZA (1949), t. II, p. 404. 
En esta larga cita se expresan toda una serie de prejuicios sobre el indígena como paradigma (negativo) en contraposición al tipo ideal, el europeo. Mantegazza matizaba estos comentarios mencionando también la belleza física de ciertas razas indígenas, la templanza en la comida, la agudeza visual y el amor a la libertad. Pero cada una de estas «virtudes» que se perciben tiene su contracara en otras descripciones donde se verifica, por ejemplo, la lascivia sensual, la intemperancia, demostrada por los «atracones» cuando hay comida en abundancia, la indolencia y hasta la pobreza de sus realizaciones técnicas y estéticas ${ }^{25}$.

El contacto con diferentes indígenas y la visión de la «realidad» le permitía a Mantegazza discutir irónicamente la tesis del buen salvaje: «Los filósofos que sobre una elástica poltrona, entre la estudiada lujuria de la vida civilizada, lamentan la libre y desnuda civilización del salvaje, deberían dar una vuelta por la Pampa argentina o llegar hasta Corrientes, para verificar si la civilización ha hecho degenerar al bípedo sabio de Linneo. Quisiera preguntarles si estas criaturas de color barroso, desnudas y cubiertas de asquerosos harapos, con músculos débiles, cabellos sueltos y sucios, devorados por un tropel de insectos, son los representantes de la inocencia primitiva o de la libertad» ${ }^{26}$.

Mantegazza por otra parte no era un viajero cualquiera. Su formación académica, sus capacidades intelectuales y la erudición tan tempranamente demostrada —el libro cita más de cuatrocientos autores, muchos contemporáneos y también fuentes históricas de relevancia - le forjan como un etnólogo fuera de lo común. Su problema, por otra parte común a toda una serie de especialistas positivistas, es la deformación consciente o inconsciente que hace de la información recogida. Para él, occidental del siglo XIX, los indios no tenían lugar en el mundo estructurado por las fuerzas del progreso arrollador de la ciencia y de la técnica. A partir de esta base teórica el texto dibuja coherentemente la inferioridad nativa, con pruebas que Mantegazza obtenía de su experiencia particular. Un «yo» vívido atraviesa las Cartas médicas y le impone al lector la verdad de los hechos, expresando en el «estar ahí» la energía de la presencia, la irrefutabilidad de la realidad tal cual $\mathrm{es}^{27}$.

Mantegazza señalaba incluso un contacto directo con indígenas mapuches (araucanos de la Pampa), ya que estuvo en la visita de la comitiva enviada por Calfucurá a Paraná para entrevistarse con Urquiza, presidente de la Confederación Argentina. El médico italiano explicaba que Urquiza colmó a los indios de presentes para que no asolaran la provincia de Santa Fé y Córdoba en su retirada y que a pesar de ser reyes o hijos de reyes, fueron alojados en corrales: «...los visité y permanecí largo tiempo con ellos, olvidando por amor a la ciencia, que todos eran ladrones y asesinos y que

25 Ibidem, pp. 406-409.

26 Ibidem, p. 405.

27 Ver la idea de verosimilitud de GEERTZ, C. (1989) respecto a la escritura antropológica de LéviStrauss, Malinowski, Benedict y Evans-Pritchard (El antropólogo como autor, Barcelona). 
el código penal íntegro habría tenido en ellos digna aplicación ${ }^{28}$. Los araucanos son descriptos de acuerdo al imaginario europeo como los habitantes de las llanuras interminables, de desiertos sin fin. Su fisonomía representa tanto la furia y la ferocidad como la impasibilidad y reconcentración y en ambos casos, Mantegazza encuentra resabios de salvajismo contrarios a la civilización.

En el siglo XIX, la fisiognomonía aparentaba ser la disciplina capaz de resolver en su totalidad todos los secretos guardados por la naturaleza humana. Sin acordar que el estudio fisonómico fuera cualitativo o cuantitativo, Mantegazza aducía que con él sería posible conocer las razas humanas y clasificar cada una de ellas de acuerdo a sus caracteres físicos y morales. La obra de Samuel G. Morton sobre craneología de los aborígenes de Norte y Sur América ${ }^{29}$, le servía como base para intentar un primer aporte sobre la fisiognomía de las razas indígenas, las que consideraba como modelo de frialdad e inmovilidad. También los estudios de Cesare Lombroso sobre antropometría criminal determinaban una apariencia particular entre los delincuentes y anomalías en la sensibilidad, lo cual llevaba a este investigador positivista a considerar los rasgos atávicos que emparentaban los «anormales» es decir, los inadaptados a la sociedad, con los «salvajes» ${ }^{30}$.

Los casos recopilados por Mantegazza sobre semblantes de indígenas eran consecuentes con las teorías lombrosianas. Los rostros impasibles de araucanos y pampas se proponían en contraposición con la fisonomía anormalmente vivaz del negro y la elevada expresión del europeo. Así, expresaba que cuando visitó al cacique Coliqueo, éste no se inmutó en lo más mínimo frente a las lisonjas que le dirigían él mismo y el coronel Baigorria, su traductor. También, que el hijo del cacique de Calfucurá, famoso por su crueldad, permaneció totalmente impávido y sumido en la más profunda indiferencia en el palco del teatro de Paraná, donde se hacía una representación de una comedia, reaccionando apenas ante la enorme variedad de estímulos visuales, la música, los decorados y la gente que lo rodeaba ${ }^{31}$. Estos y otros casos similares, junto con una serie de dibujos de mulatos, blancos y mestizos y de indígenas tobas, calchaquíes y chiriguanos, le permitían afirmar científicamente las diferencias marcadas entre indios, blancos y negros. En el rostro y el carácter cada raza llevaba escrita indefectiblemente una marca propia y el estudio de multitud de casos como los que detallaba permitiría en el futuro configurar un verdadero «mapa» antropológico-racial.

Para Mantegazza, la esencia indígena se manifestaba en la impasibilidad y en la incapacidad de responder con normalidad a los estímulos nerviosos. El indio estaba impedido fisiológicamente de responder ante la belleza, porque carecía de la capaci-

\footnotetext{
28 MantegazZa (1949), t. II, p. 420.

29 Ibidem, pp. 478-479.

30 PeSeT, J. L. y PeSET, M., est. prel (1975), Cesare Lombroso y la escuela positivista italiana, Madrid, pp. 415 y 462.

31 MANTEGAZZA, (1949), t. II, pp. 440-441. 
dad estética, no podía tampoco expresarse con ternura, porque su naturaleza le negaba la posibilidad de sentir amor o piedad. Sólo podía responder ciegamente a los instintos más bajos, pero aún sin disfrutar de ellos. La crueldad y la violencia tampoco incidían en la frialdad de su carácter, que no se abandonaba a la desesperación aún en las peores circunstancias. Esta característica podría haber sido valorada positivamente, ya que después de todo concordaba con los valores de la masculinidad occidental, pero no fue así. Mantegazza la utilizaba como argumento médico que confirmaba las teorías antropológicas de inferioridad de ciertos grupos humanos.

Este médico refería entonces que «...Los indios resisten al dolor mucho más que nosotros, y he visto pruebas luminosas, al practicarles crueles operaciones de cirugía. Son extrañamente insensibles en la piel y en el corazón. También resisten mejor que nosotros a la intemperie y a los largos ayunos. Es en ellos virtud necesaria y fruto de larga costumbre, y la higiene y los cuidados solícitos no salvan la vida de los débiles y enfermizos, por lo que sólo los fuertes se hacen hombres y en el ejercicio de las privaciones se fortifican y duran». Y más adelante volvía a aseverar «...saben resistir de un modo singular a las lesiones traumáticas, y en América es popular el proverbio duro para morir como un indio» ${ }^{32}$. La representación positivista del indio es la de un ser salvaje y espartano a la vez, adaptado a las duras condiciones medioambientales, más cerca de la naturaleza y a la vez, por la pérdida de lo que se establecía como normal en la especie humana, «desnaturalizado». Lo natural asume las dos definiciones: lo biológico por un lado, parte fundamental del indio, y la negación de lo natural como anormal, fuera de lo común, medido desde el punto de vista occidental.

Los textos de otro médico, el corso José Mateo Franceschi, se acercan en varios puntos a las teorías de Mantegazza. Franceschi desgranó parte de sus interesantes hipótesis ambientales y raciales en varios artículos aparecidos en la Revista MédicoQuirúrgica (en adelante, $R M Q$ ) ${ }^{33}$, sobre todo en relación con las teorías degenerativas extendidas entre numerosos intelectuales y científicos argentinos.

Franceschi trabajó como médico durante varios años en la campaña bonaerense y también en la frontera, como médico militar, entre 1871 y 1875 . Utilizando la observación y práctica como método científico, escribió en 1886 un artículo donde observaba que los grandes traumatismos eran menos letales entre los naturales de la Pampa que entre las personas llegadas de fuera. Asimismo, en las operaciones quirúrgicas, las supuraciones se manifestaban raramente y la cicatrización era rápida por lo que «...la más pequeña herida que se eterniza en las manos de ingleses o alemanes, ni caso hace al criollo» ${ }^{34}$. La teoría del médico era que el territorio pampeano carecía en

\footnotetext{
32 Ibidem, pp. 405-406. En cursiva en original.

$33 \mathrm{La} R M Q$, una de las primeras y principales publicaciones médicas, fue fundada en 1864 por los médicos Angel Gallardo y Pedro Mallo. Se publicó hasta 1888, siendo posteriormente sustituída por otra publicación similar, La Semana Médica. A partir de 1879 fue dirigida por el eminente higienista Emilio Coni.

34 FrANCESCHI, J. (1886a), «La cirugía en la Pampa Argentina», RMQ, XXIII, nº 10, p. 154.
} 
general de minerales tónicos, sobre todo de hierro. Esto provocaba en sus habitantes una constitución débil que los hacía ineptos al trabajo pesado y a la actividad intelectual. La degeneración racial podía ser observada científicamente de mil maneras, entre las que Franceschi citaba una necesidad de comer y dormir más de lo habitual, la pudrición anormal de productos agrícolas e incluso un índice menor de nutrición en la leche materna. Las enfermedades más comunes que se presentaban eran, entre las mujeres, la clorosis y la debilidad estructural, predominando familias enteras de escrofulosos y tuberculosos.

La razón de todos estos males estaba entonces en la falta de hierro, que él proponía subsanar a través de su incorporación en los pozos de agua. No se sabe si esta práctica se llevó a cabo, pero fue más por imposibilidad técnica que por desacuerdo científico ya que había en el medio académico un consenso general acerca de las virtudes del hierro, en lo que podríamos llamar, parafraseando a Kuhn, un «paradigma» de la causalidad de las enfermedades debilitantes ${ }^{35}$. Franceschi atribuía la mejor cicatrización entre los naturales de la Pampa a la falta de hierro y esa misma afirmación — es decir, que la debilidad fuese positiva—, daba pie a una paradoja que el médico no podía resolver. Para él, la pobreza del hierro en la sangre permitía una menor inflamación y así los nativos envejecían mejor, encanecían menos, conservaban los dientes y cabellos más tiempo ${ }^{36}$. Esta aseveración estaba en abierta contradicción con su propia teoría acerca de la escasez ferruginosa y la debilidad estructural de los habitantes pampeanos, pero Franceschi no la profundizaba ni intentaba rehacerla, sino que avanzaba para probarla a partir de experimentos quirúrgicos.

Así, expresaba que realizó varias operaciones de cataratas entre pobladores del interior bonarense y salvó a un indio de la muerte al improvisar en un hospital de campaña una complicada técnica de sutura y entablillamiento del cuello. Franceschi explicaba que en el mismo frente de batalla y en la isla Martín García, donde fueron confinados los indígenas, debió curar las horribles heridas producidas por las lanzas en los soldados y en los mismos indios aliados al ejército. En una ocasión, uno de los prisioneros quizo huir y fue herido de gravedad por las tropas nacionales por lo que pudo ejercitar en él un método novedoso para sostenerle el cuello casi separado de la cabeza, detallado en la publicación médica.

35 El cónsul francés A. Peyret se maravillaba a finales del siglo XIX ante la tierra de Misiones, de rojo subido, cuyo alto contenido en material ferruginoso aseguraba, según sus impresiones, la salud y bienestar a sus habitantes. En PEYRET, A. (1889), Une visite aux colonies de la Republique Argentine, París, p. 34. También testimonian esta aseveración la diversidad de medicamentos que contenían hierro y que se recetaban en general para enfermedades de la sangre y estados de caquexia, así como para el tratamiento de la tuberculosis, escrofulosis, clorosis y anemia. Como ejemplo, ver el «Ferrovose» (Argentina Médica, Semanario de Medicina Práctica, Buenos Aires, Año X, n 29, 1912) y los «comprimidos» del Doctor Puiggari (Revista de la Sociedad Médica Argentina, Buenos Aires, 1902).

36 FRANCESCHI (1886a), p. 154. 
El médico testificaba que cualquier blanco hubiera muerto ante aquel traumatismo pero que el indio se salvó en parte por su solicitud y en parte por su propia constitución. Franceschi no actuaba solamente llevado por el juramento hipocrático, es decir, porque se trataba de un hombre enfermo que necesitaba cuidado, sino porque tal como él mismo señaló, «...la satisfacción de ver una curación completa por primera intención en pocas días debía compensar el esfuerzo», y eso a pesar de que todos los que observaban su preocupación le decían «...jtanto trabajo para un indio!» ${ }^{37}$. El médico continuaba su relato especificando la cura de cincuenta y dos indios de la tribu de Catriel que también se salvaron, por lo cual podía afirmar que «...las condiciones vitales del natural de la Pampa Argentina son muy favorables al éxito de las grandes operaciones $»^{38}$.

El hecho de que los indios se transformasen en cuerpos para realizar experimentos está unido a la ideología de la diferencia inferiorizante y consecuentemente a la extinción a partir de «leyes naturales» aplicadas por los darwinistas sociales. Franceschi acordaba en general con esta concepción, común a un auditorio médico que escribía y leía publicaciones científicas como la $R M Q$. El médico señalaba así que «... los argentinos los desconocen (a los indios) como hijos de Adán y sin discutirles si su raza india es aborigen o asiática, los persiguen, los expulsan o los someten, con el noble fin de sustituir la cultura del salvajismo» ${ }^{39}$. En «los argentinos» había una autoinclusión, porque el autor no era tal, pero compartía con la élite intelectual nacional la mayoría de las suposiciones generales acerca de la conformación étnica ideal; es decir, la de un país sin indios, con blancos libres de la sangre débil de los nativos.

Otra de la tesis de Franceschi, sustentada con pruebas tan débiles como las anteriores, era justamente el control étnico. Las uniones consanguíneas, propias según el autor de los indígenas, acarreaban una descendencia defectuosa y muchas posibilidades de contraer la tuberculosis. El médico explicaba que entre los indios no podía haber selección natural, y las uniones entre parientes eran inevitables, comprendiendo cretinos, idiotas y desgraciados incapaces, lo que explicaba su decadencia y extinción. Por lo tanto aconsejaba no casarse entre parientes «...y lo menos posible entre connacionales de antiguas generaciones americanas» ${ }^{40}$.

La encadenación sucesiva de razonamientos erróneos, que van desde la falta de hierro, la debilidad de los nativos, la consanguinidad y la tuberculosis, estaban justificados en el texto a partir de un elemento fundamental que formaba parte del conjunto de saberes legítimos de la comunidad académica y que por lo tanto, Franceschi no necesitaba probar empíricamente: la inferioridad indígena. A partir de allí, todas las partes

37 Ibidem, p. 184.

38 Ibidem, p. 186.

39 Ibidem, p. 185.

40 FrANCESCHI, J. (1886b), «Uniones consanguíneas y connacionales: degeneraciones antiguas como causa de degeneración de las razas en la Pampa», $R M Q$, XXIII, nº 18, pp. 279-281. 
se situaban en los lugares correctos y a pesar de que varias de sus aseveraciones hacían agua y eran incompatibles entre sí, tendían a formalizar en el conjunto científico al nativo como ser insensible, cuyo cuerpo, vivo o muerto, pertenecía más a la ciencia que a sí mismo.

\section{ENSAYOS Y COMPROBACIÓN MÉDICA}

Tal como Mantegazza y Franceschi, el francés Benjamín Dupont confirmaba, si bien de otra manera, la conversión del indígena en objeto experimental. También médico en la línea de frontera, específicamente en Villa Mercedes (San Luis), participó en la Campaña al Desierto como profesional sanitario. Dupont contribuyó en varias oportunidades a la $R M Q$, que publicó elogiosamente sus trabajos ${ }^{41}$.

En su marcha con el ejército, Dupont «...no pierde oportunidad para practicar los estudios con que (la ciencia) pueda enriquecerse. No solamente tiene en su poder una descripción detallada de todos los vastos territorios que ha recorrido, y hasta hoy desconocidos, sino que también ha reunido multitud de objetos (...) cráneos frescos y disecados $(\ldots)$ como también plantas que gozan de importantes propiedades terapéuticas que él ha tenido ocasión de observar» ${ }^{42}$. La recolección de material antropológico y botánico estaba de acuerdo con la concepción médica de la época, así como la experimentación in situ.

Los mayores aportes de Dupont se dirigieron a la investigación sobre la teniasis, endemismo de la campaña pampeana. En un artículo presentado ante el Círculo Médico Argentino, el médico explicaba que cuando fue cirujano del ejército entre 1875 y 1877 , de un total de 500 soldados y 500 indios amigos, diagnosticó 271 afectados por el parásito de Tenia solum. Este resultado tan alarmante lo llevó a prestar atención a la enfermedad, por lo que cuando actuó como cirujano del ejército en 1878-79 aprovechó «...esa oportunidad para proseguir mis investigaciones sobre la tenia entre los indios que eran tomados prisioneros, que se guardaban durante meses en el Campamento general» ${ }^{43}$.

Consultando al resto de sus colegas de otras divisiones del ejército, Dupont comprobó también el endemismo entre los nativos pampeanos y se dispuso entonces a

41 Una biografía de B. Dupont puede consultarse en VACAREZZA, O. (1967), «De la vida y obra del Dr. Benjamín Dupont, caballero de la Legión de honor, cirujano de la frontera y del desierto», Boletín de la Academia Nacional de Medicina de Buenos Aires, 45, pp. 557-576. Dupont formó parte del grupo de higienistas que transformó significativamente el panorama sanitario nacional. Escribió también artículos sobre la cremación y la prostitución en Buenos Aires, con un criterio reglamentarista.

$42 R M Q$, año XVII, $\mathrm{n}^{\circ} 10,1879$, p. 154.

43 Dupont, B., (1885), Endemia de la Tenia Solum en la República Argentina. Estudio sobre sus modos de propagación y expulsión, Buenos Aires, p. 10. 
buscar una hipótesis que avalara esta observación, concluyendo que la teniasis era frecuente por la ingestión de gérmenes del cisticerco presentes en la carne cruda ${ }^{44}$. La carne era un alimento común en la Pampa y mientras que los indios consumían la de yegua o potro cruda, los gauchos y soldados lo hacían de ganado vacuno cocida en forma insuficiente.

Dupont encontró en su primer experimento, realizado entre 1875-77, casi un 30\% de personas con teniasis, pero en su análisis final no aclaraba cuales eran blancos y cuales indios. Ahora bien, un punto interesante es la metodología que pudo utilizar en 1879 , cuando se encontraba en un campamento militar y se dispuso efectivamente a investigar sobre el tema con el fin de probar su teoría. Según el médico, la bibliografía reconocía numerosas pruebas sobre la ingestión de cisticercos y el desarrollo de tenia y específicamente un investigador, el Dr. Küchenmeister, había hecho tragar a un condenado a muerte varios cisticercos, encontrando posteriormente en la autopsia tenias en desarrollo ${ }^{45}$.

Si bien la forma en que el susodicho especialista europeo experimentó con un ser humano era un llamado de atención a la ética médica, no recibía ninguna crítica en Dupont. Este quizás asumía dicha investigación como legítima, puesto que pensaría que no estaba mal que una persona fuera expuesta a dar en vida su cuerpo a la ciencia, ya que muy pronto moriría y por lo tanto no sentiría los efectos de la experimentación, brindando así un indiscutible apoyo al avance científico. ¿Esto sugiere que él, entre los indios de la Pampa hubiese aplicado este método, haciéndoles ingerir carne contaminada para después verificar las tenias en sus cadáveres? Dupont no dice que hizo tal cosa, pero (y el pero no deja de ser importante) estaba ante un conjunto de personas «condenadas a muerte», ya fuese por causas «naturales» - la viruela sobre todo, enfermedad mortal en la mayoría de los casos-, como por exterminio directo del ejército. Sobre todo, compartía la noción generalizada en distintos medios intelectuales sobre la inferioridad indígena, así como asumía la necesidad del progreso científico-médico, un fin demasiado importante para la ciencia positivista para ser llevado a cabo por cualquier medio que se presentara.

Por último Lucio Meléndez, médico alienista, analizaba también en la $R M Q$ la locura entre los indígenas, elaborando un curioso material interpretativo. En el siglo XIX, los estudios sobre lo que se denominaba indistintamente frenopatía o enfermedades nerviosas asumieron un status científico preponderante, sobre todo por su conexión con la noción de responsabilidad legal y política. Las enfermedades mentales se vincularon cada vez más a disfunciones o problemas biológicos, dejándose de lado las interpretaciones religiosas que las diabolizaban. Por lo tanto era lógico que la

44 Ibidem, p. 31

45 Ibidem, p. 25. 
ciencia reclamara su estudio y aun su curación en centros especiales, donde los enfermos retornarían a su anterior identidad social e individual ${ }^{46}$.

Lucio Meléndez era en 1880 el director del Hospicio de las Mercedes, una de las pocas instituciones existentes en esa época para la atención de enfermos mentales ${ }^{47}$. Por entonces, los médicos habían comenzado a observar un crecimiento constante del número de alienados en las áreas urbanas, a lo cual buscaban una explicación. El supuesto acrecentamiento de alienados en la Argentina fue una de las principales preocupaciones de los médicos y psiquiatras positivistas, reflejado en estudios que intentaron «medir» el fenómeno cuantitativamente.

Una de las primeras investigaciones al respecto fue justamente un trabajo estadístico realizado por Emilio Coni y Lucio Meléndez en 1880, donde se prestaba atención al número de enfermos psiquiátricos y retardados mentales, considerando ambas categorías por separado ${ }^{48}$. Esta cantidad anormal de enajenados se debía según ellos al impacto de la vida moderna y a los vicios que esta conllevaba sobre formas de vida tradicionales, así como a una conformación interna propensa a la locura, evidenciada en las «razas inferiores».

En la $R M Q$, Meléndez reflexionaba entonces por qué luego de la Campaña al Desierto no había habido un mayor número de indígenas internados en su centro, habida cuenta de que estuvieron sometidos a «...variadas y múltiples causas que someten a la enajenación en las razas civilizadas. Azotados por el enemigo en todas partes, desalojados de sus hogares para buscar una guarida donde ocultarse, sufriendo penurias de todo género, han podido resistir valerosamente a tales acontecimientos sin perder la razón y no se dirá que su organismo robusto y fuerte los pone a salvo de contraer las vesanias y que educados bajo un sistema militar, están menos predispuestos que los habitantes de la ciudad» ${ }^{49}$.

A diferencia de otros especialistas, Meléndez consideraba a los mapuches biológicamente similares a los blancos y negros, por lo que debía buscar las causas de una salud mental excepcional no en el organismo de los indígenas, sino en el entorno y en las experiencias a las que habían estado sujetos. El médico preguntó a varios jefes del ejército - no dice cuáles - sobre alienados entre los prisioneros indígenas. Uno de ellos le refirió que luego de su captura, un joven quizo huir y en virtud de las ideas absurdas que tenía y la incoherencia de su conversación, concluyeron sobre su locu-

46 Cf. HuERTAs, R. (1992), Del manicomio a la salud mental. Para una historia de la psiquiatría pública, Madrid, p. 39; FouCAult, M. (1976), Historia de la locura en la época clásica, México, sobre todo en el T. II el capítulo «Nacimiento del asilo».

47 Una síntesis de las instituciones psiquiátricas en Argentina puede consultarse en INGENIEROS, J. (1920), La locura en la Argentina, Buenos Aires, sobre todo pp. 218-221.

48 CONI, E. y MELÉNDEZ, L. (1880), Consideraciones sobre la estadística de la enajenación mental en la Provincia de Buenos Aires, Memoria leída en el Congreso Internacional de Ciencias Médicas, Amsterdam.

49 MeLÉnDEZ, L. (1880), «Los indígenas y la locura», RMQ, XVII, nº 2, p. 34. 
ra. Este indio dijo que iba a «...evadirse merced al gualichu de que disponía para burlar la vigilancia» y murió al querer volar más allá de las trincheras del fortín ${ }^{50}$. Al margen de cualquier interpretación etnológica sobre las creencias mapuches, para Meléndez el indio no estaba loco sino que interpretaba su delirio como producto de la fiebre que debía tener puesto que había sido herido.

Otro caso, el único que había podido estudiar en el Hospital donde era director, era el de una mujer que presentaba el cuadro de una «lipemaníaca», aborreciendo a todas aquellas indias que no eran de su nación. Simplificadamente Meléndez decía que la paciente debía ser chilena (es decir, mapuche de la Araucanía) y que por lo tanto, era contraria a aceptar a las otras mujeres de origen argentino (mapuche de las Pampas), asumiendo en ella un odio nacionalista consecuente con la postura bélica en los años '80, cuando Argentina y Chile estuvieron muy cerca de una confrontación bélica a raíz de los territorios patagónicos.

Por último, Meléndez citaba vagamente casos de locura entre los indios repartidos entre las familias porteñas, pero esto le parecía normal porque se trataba de habitantes cercanos a la cordillera, donde el cretinismo era frecuente. Esta noción, base de un prejuicio generalizado sobre la población del interior, fue común también en otros textos médicos ${ }^{51}$. Para Meléndez, el cretinismo se relacionaba - como en el caso de Franceschi- con la consanguinidad y en consecuencia podía ser una característica negativa común a los indios y a otros habitantes de la campaña ${ }^{52}$.

De este artículo es verdaderamente curiosa la ausencia del objeto de estudio, de la cual era consciente el propio investigador. Meléndez no explicaba en consecuencia por qué no había indios locos y los pocos alienados que lograba citar indudablemente no lo convencían para definir una teoría. Por lo tanto, terminaba el artículo «...con la esperanza de que no estaría quizás muy lejano el momento en que podamos observar algunos casos prácticos de indígenas insanos que nos permitan presentar algún cuadro importante como materia de estudio para los que deseen dedicarse a esta especialidad o hasta que los cirujanos militares nos den algunos datos al respecto, ya que han estado en la Campaña al Río Negro» ${ }^{53}$. La forma de enunciar un futuro camino para la investigación era sin duda poco inusual, ya que justamente la medicina tiene como objetivo evitar la enfermedad, no desear que ocurra para poder estudiarla.

El médico alienista proponía similitudes biológicas para blancos e indios, - - los dos tienen pulmones y también cerebro- y creía que lo que se denomina un «shock»

50 MELÉNDEZ (1880), p. 35. El «gualicho» o walicho es para los mapuche el «daño», es decir, la enfermedad, muerte o mala suerte que se introduce en el cuerpo de una persona, a partir generalmente de hechicerías. Ver al respecto FOERSTER, R. (1993), Introducción a la religiosidad mapuche, Santiago, pp. 101-108.

51 Ver también RAMOs MEXíA, J. M (1974), Las multitudes argentinas, Buenos Aires, pp. 153-154 y Ayarragaray, L. (1912), «La constitución étnica y sus problemas», Archivos de Psiquiatría y criminología aplicadas a las ciencias afines, Año XI, p. 31.

52 MELÉNDEZ (1880), p. 36

53 Ibidem. 
psicológico de gran magnitud, como perder absolutamente todo lo que da sustento a la vida, provocaría en cualquier ser humano un extravío mental considerable. En ese sentido avanzaba mucho más que Dupont, Franceschi o el mismo Mantegazza sobre la unidad indiscutible de la especie humana. Pero al mismo tiempo, el afán por estudiar científicamente impulsaba la creación del objeto de estudio, para dar así lugar al alienismo indígena como nueva especialidad, lo cual, por diversas circunstancias relacionadas con la integración de la población nativa, nunca sucedió.

\section{REFLEXIONES FINALES}

Tal como ha observado Pedro Laín Entralgo, la objetivación del cuerpo humano a través de la investigación y el diagnóstico médico fue un proceso iniciado en el mundo occidental en el siglo XVIII, que alcanzó gran importancia en el siglo XIX. A partir de la denominada «mentalidad anátomo-clínica», los pacientes perdieron su calidad de sujetos y se transformaron en objetos de estudio médico ${ }^{54}$. Este fenómeno no era nuevo, ya que la medicina tuvo siempre que asumir la contradicción entre persona enferma-enfermedad, es decir sujeto y objeto a la vez, pero la constitución del enfermo como «ente de la naturaleza» se implicó profundamente en la ciencia positivista. Todo un conjunto de pacientes, sobre todo los más pobres y desfavorecidos, fueron tratados como objetos enfermos o sanos, a los que valía la pena diagnosticar y diseccionar y no necesariamente cuidar y curar.

Para los especialistas médicos, la eficacia técnica implicaba necesariamente esa objetivación, que se traducía en ventajas en la investigación científica. Por otra parte, esto permitió legitimar experimentos realizados sobre seres humanos, afirmando asimismo una diferencia desvalorizante en determinados grupos y sociedades. En el caso de la compleja relación entre positivismo e integración indígena en Argentina, es interesante observar no sólo la generación y consolidación de ideologías cientificistas que establecían a nivel teórico la irrefutabilidad de la inferioridad indígena, sino también en la actuación concreta de determinados médicos.

Se trata sobre todo de profesionales que realizaron su tarea en sitios alejados de los centros urbanos más importantes, ya fuese en pequeños poblados del interior argentino, donde había población indígena y mestiza, en las campañas militares efectuadas en los años ' 80 o bien que tuvieron contacto directo con los «vencidos», es decir, con los indígenas derrotados y recluidos bajo el control blanco, en diversas instituciones sanitarias. Mantegazza accedió posteriormente, a su regreso a Italia, a un status profesional mayor al que tenía en Argentina durante los años '50, cuando

54 Laín ENTRALGO, P. (1964), La relación médico-enfermo. Historia y teoría, Madrid, pp. 201-202. 
intentaba obtener un puesto público ${ }^{55}$. Otros, como Dupont y Franceschi, si bien pudieron difundir sus ideas en una importante publicación médica, no estuvieron dentro del núcleo de médicos notables que participaron activamente en distintos gobiernos y formaban parte de la élite social argentina ${ }^{56}$. Meléndez por su parte tuvo mayor incidencia académica y pública que los tres restantes como director de un hospital y profesor universitario e iniciador de estudios e investigaciones psiquiátricas en Argentina, aunque tampoco pueda ser considerado dentro del sector de médicos prestigiosos.

Esta cuestión singular los aproxima entonces a un conjunto informe de «médicos del común», que desarrollaban su tarea lejos de las ciudades más importantes y de los centros intelectuales de relevancia, de los cuales como es obvio se sabe muy poco. Existen importantes coincidencias ideológicas entre ellos y los que podríamos denominar «notables», unificando las conciencias a nivel científico en relación con las teorías positivistas europeas, sobre todo respecto a la degeneración racial. El intento por comprobar empíricamente la subordinación de los «salvajes» implicó el descubrimiento de la insensibilidad corporal y psíquica, unida a un desarrollo físico anormal y a una fisonomía diferencial, marcadamente anómala y ancestral. Esta cuestión legitimaba una actuación profesional discutible éticamente, enraizada en el saber per se sin considerar los perjuicios físicos o psíquicos del enfermo.

Por otra parte no debe olvidarse que, paralelamente, se produjo en Argentina y sobre todo en la Región Pampeana, la conquista militar de territorios que habían estado durante siglos bajo dominio de diversas parcialidades indígenas. Es difícil establecer su peso demográfico anterior a la campaña pero en general, los mismos contemporáneos aceptaron su desaparición, a la cual dieron distintas explicaciones. La mayoría de ellas justificaban esta pérdida escudándose en razones científicas, validadas sobre todo por las ciencias médicas.

55 Mantegazza mantuvo correspondencia con un importante intelectual y político argentino, Juan M. Gutiérrez, ministro y rector de la Universidad de Buenos Aires. El contacto entre ambos se inició en 1855, cuando Mantegazza escribió al funcionario para pedirle un empleo público que le permitiese dejar la profesión médica e iniciar un «análisis natural del hombre moral» y continuó durante varios años. $C f$. Moglia, R. y GarcíA, M. (ed.) (1982), Archivo del Dr. Juan María Gutiérrez. Epistolario, Buenos Aires, t. III, pp. 153-154.

56 Ver al respecto GONZÁLEZ LEANDRI, R. (1999), Curar, persuadir, gobernar. La construcción histórica de la profesión médica en Buenos Aires, 1852-1886, Madrid. Dentro de esa élite pueden mencionarse en un primer lugar a Juan, Manuel y Leopoldo Montes de Oca y F. Muñiz y posteriormente a O. Rawson, E. Wilde, J. M. Ramos Mexía y E. Coni, entre otros. 